\title{
Digame Licenciado... Un punto de vista \\ sobre los puntos de vista en torno a la definición de «traductor» en el proyecto de ley traducción autoral en Argentina
}

yu LAURA Fólica / Universitat Pompeu Fabra / laurafolica@gmail.com

\section{Resumen}

Desde el marco teórico de la sociología de los bienes simbólicos elaborada por Pierre Bourdieu, nos proponemos estudiar los distintos puntos de vista sobre la definición de «traductor» en el artículo 2 del proyecto de ley de Derechos de los Traductores y Fomento de la Traducción en Argentina (expediente 4852-D20I5). Tras describir el punto de vista del analista, revisaremos las distintas tomas de posición en relación con el proyecto, las posiciones y disposiciones de los agentes que intervienen en el debate. Nos centraremos en el estudio de los dos grupos opositores (formadores universitarios y graduados colegiados). Para ello, analizaremos su estrategia de numerus clausus (exigencia de título habilitante para ser traductor/a) y el efecto de alodoxia que reproducen al exigir una titulación en un espacio que se rige más bien con la lógica del campo creador.

\section{Palabras clave: sociología de los bienes simbólicos}

- Bourdieu - Proyecto de Ley de Derechos de los Traductores y Fomento de la Traducción • titulación • colegiación

\begin{abstract}
From the theoretical framework of Pierre Bourdieu's Sociology of Symbolic Goods, we will study the different viewpoints on the definition of «translator» in article 2 of the Translator Rights and Translation Promotion Law Project in Argentina (record 4852-D-2015). After describing the analyst's point of view, we will review the various stances taken in connection with the project, i.e. the positions and dispositions of the agents involved in the debate. We will focus on the study of the two dissenting groups (academic trainers and collegiate graduates). To achieve this, we will analyze their numerus clausus strategy (requirement of a specific degree to be a translator), and the effect of alodoxia reproduced by requiring a specific academic degree in a space that falls rather within the logic of the creative field.
\end{abstract}

Key words: sociology of symbolic goods $\cdot$ Bourdieu - Translator Rights and Translation Promotion Law Project $\cdot$ academic degree $\cdot$ collegiate membership 
En septiembre de 20I3, un grupo de traductores argentinos presentó al Congreso de la Nación un proyecto de ley para la protección de los traductores que realizan una «traducción autoral», es decir, una obra derivada de otra obra sujeta a derechos de autor. ${ }^{1}$

La idea no es nueva. La defensa de la autoría del traductor ya está presente desde fines del siglo xIx en marcos legales internacionales como el Convenio de Berna para la protección de las obras literarias y artísticas de I886, ampliado, luego, en la Recomendación de Nairobi sobre la protección jurídica de los Traductores y las Traducciones de 1976. En el espacio europeo actual, las recomendaciones de la Plataforma Europea para la Traducción Literaria (20II) y el código de buenas prácticas del Consejo Europeo de Asociaciones de Traductores Literarios (20II) apuntan en la misma dirección. Además, muchas leyes nacionales sobre propiedad intelectual definen al traductor como autor; en el ámbito del castellano, esto ocurre en Bolivia, Colombia, Costa Rica, Educador, España, El Salvador, Guatemala, México, Nicaragua, Panamá, Paraguay, Perú, República Dominicana, Venezuela. ${ }^{2}$ En Argentina, nuestra vieja aunque pionera ley de propiedad intelectual $\mathrm{N}^{\circ}$ II.723, de 1933, protege a los autores de obra tanto en sus derechos morales (o subjetivos) como patrimoniales (o pecuniarios); lo mismo sucede con los traductores, cuyos derechos son reconocidos en el artículo $4^{\circ}$, inciso c: «son titulares del derecho de propiedad intelectual (...) los que con permiso del autor la traducen, refunden, adaptan, modifican, o transportan sobre la nueva obra intelectual resultante». Sin embargo, en el artículo 38 se señala una excepción, que el mercado editorial ha transformado en norma, al menos en lo que respecta a traducciones: «el titular conserva su derecho de propiedad intelectual, salvo que lo renunciare por el contrato de edición».

Gracias a esta excepción, la renuncia por tiempo indeterminado de los derechos patrimoniales de los traductores es frecuente en los contratos de adhesión que el traductor suele firmar con las editoriales. Aquí y ahora se aceptan cesiones para todo el ámbito de la lengua y por los tiempos de los tiempos; con cláusulas que indican que «el traductor cede al editor, en exclusividad, para todo el mundo y por tiempo indeterminado, todos los derechos que le corresponden sobre su traducción de la obra». ${ }^{3}$ Otros editores limitan un poco sus aspiraciones señalando, primero, el enajenamiento de los derechos patrimoniales y, luego, como «contraparte», el reconocimiento del nombre del traductor como un derecho moral inalienable:

A cambio de la suma recibida de acuerdo con la cláusula $\mathrm{x}$, el traductor cede totalmente al editor la titularidad de los derechos patrimoniales que le correspondan respecto de la totalidad de su traducción (...). En contraparte, el editor se compromete a consignar en la página cuatro (vuelta de portadilla) de la edición el nombre completo del traductor.

¿Acaso la negación de un derecho puede ser compensando con el reconocimiento de otro? Así pues, lo que la ley expulsó por la puerta en el artículo 4, 
ingresa por la ventana de las prácticas cotidianas amparadas en el artículo 38. De este modo, el traductor de libros, con su firma de cesión de los derechos patrimoniales, niega la relación que tiene con su obra luego de haber sido remunerado en el momento de producción; se vuelve un progenitor cuyo apellido se transmite al vástago siempre que se mantenga a distancia prudencial por el resto de los días.

Ante este panorama, un grupo de traductores (compuesto por formadores, investigadores y traductores profesionales) elaboraron un proyecto de ley que, en lugar de tratar de modificar una amplia ley de propiedad intelectual, tarea engorrosa por la multiplicidad de actores que afecta, se acota a un ámbito específico - a semejanza de otros proyectos de leyes singulares de trabajadores culturales como los actores, los ilustradores o los bailarines de danza, etc.- - y propone un modelo de contrato con cláusulas claras sobre los derechos morales y patrimoniales del traductor (ámbito y plazo de autorización de uso, pago por adelanto de derechos, etc.), así como medidas de fomento y visibilización de la profesión. ${ }^{4}$ El proyecto de 2013 caducó transcurridos los dos años de plazo previsto sin tratamiento parlamentario y se volvió a presentar en 2015 con modificaciones que fueron fruto del debate sostenido en esos años (expediente 4852-D-20I5). Contó con el aval de diez diputados de distintos partidos políticos y unas 1750 adhesiones de personalidades, estudiantes y trabajadores de la cultura, nacionales y extranjeros, así como de diversas editoriales pequeñas y medianas y de colectivos como la Federación Internacional de Traductores, la Asociación de Traductores Literarios de Canadá, el Consejo Europeo de Asociaciones de Traductores Literarios, el Consejo Directivo de Filosofía y Letras de la UBA, la Sociedad Argentina de Escritores, etcétera.

Como traductora literaria, integré el grupo del segundo proyecto; por lo tanto mi parti pris es evidente. Ahora bien, no creo que este hecho impugne mi punto de vista sobre la cuestión, ya que en estas páginas no busco hacer una defensa acalorada de su letra ni apelar a las vías del conmover o del convencer para levantar adhesiones. Por el contrario, la cercanía con el proyecto me ha movido, no a polemizar, sino a tratar de comprender por qué se generaron fuerzas opositoras dentro del propio campo de los traductores; reacción más inesperada que el previsto rechazo por parte de cámaras editoriales, que ven en el reclamo laboral de un sector subalterno la ruina de la industria editorial del país todo.

Tal y como señalaban Pierre Bourdieu (I984:72), el «privilegio del sociólogo» (y por extensión del analista en Ciencias Sociales, entre las que podríamos ubicar los Estudios de Traducción) es estar presente como "objetivador participante», esto es, no ocultarse tras una supuesta objetividad que no haría más que reproducir la doxa en un análisis espontáneo, sino participar a partir de una interrogación, primero, de su propio punto de vista, para luego pasar a los otros puntos de vistas parciales que están en juego.

Así pues, primero lo primero: ¿cuál es mi posición en el campo de la traducción? Me dedico a la traducción literaria profesional (trabajo para la industria editorial y audiovisual) y académica (doy clases e investigo sobre traducción) 
desde 2005. Me gradué en Ciencias de la Comunicación (UBA) y traducción (IES en Lenguas Vivas "J. R. Fernández») y me especialicé en literaturas comparadas y traducción literaria (en una maestría y un doctorado en la Universitat Pompeu Fabra). Este perfil me ubicaría dentro de cierta heterodoxia, ya que no me dedico a «tiempo completo» a ninguna de las actividades que realizo y, por lo tanto, ocupo más bien una posición marginal tanto en el mercado de trabajo como, sobre todo, en la academia, la cual no suele puntuar muy alto las traducciones de libros como parte del trabajo intelectual de sus miembros. Practico y pienso la traducción. Por eso, colaborar con un proyecto de ley sobre la protección de los derechos de los traductores en Argentina me interpeló como «traductora que investiga» y a la vez como «investigadora que traduce». Desde aquí miro.

Y me pregunto. Me propongo, entonces, interrogar los puntos de vista sobre la figura del traductor que están en pugna en torno al proyecto de Ley de Derechos de los Traductores y Fomento de la Traducción (LDTyFT). Acudiendo a la sociología de los bienes simbólicos de Bourdieu como herramienta de análisis, el objetivo es desarmar la homogeneidad aparente en la idea de "profesión" y situar a los traductores como agentes dentro del campo de la traducción en Argentina, es decir, dentro de un espacio estructurado jerárquicamente, con un sector dominante y otro dominado, dinamizado por luchas para la apropiación de ciertos capitales. A partir de las tomas de posición respecto del proyecto LDTyFT, se podrá indagar en la posición que ocupan los distintos agentes y en sus disposiciones o habitus.

En su inicio, el proyecto LDTyFT define los términos a los que referirá en su texto («traducción», «traductores», «usuarios»). Así, en el artículo 2, indica que, «a los efectos de la presente ley», se entiende por "traductores»: «a las personas físicas que realizan la traducción de obras literarias, de ciencias sociales y humanas, científicas y técnicas sujetas a propiedad intelectual, cualquiera sea su formación profesional». ${ }^{5}$ Este artículo - y especialmente la aclaración final «cualquiera sea su formación»- despertó el rechazo de algunos sectores de profesores y graduados en traducción, dejando claro que la lucha de poder radica en quién se halla capacitado para establecer qué es lo legítimo en el terreno de las denominaciones. De ahí que revisar las definiciones propuestas por cada sector sea útil para advertir que estas son construcciones sociales, a pesar de que luego se naturalicen por quienes se sienten representados en ellas.

Los opositores defienden una definición a partir de un numerus clausus, limitado y homogéneo: ya sea por la titulación (es traductor el «traductor diplomado»), ya sea por la matrícula de graduados (es traductor el «traductor matriculado»). Esta estrategia restrictiva es sostenida por dos colectivos que ocupan una posición fuertemente institucionalizada (el primero de docentes, el segundo de graduados colegiados o federados), pero que también se ve reforzada por la parte dominada, los pretendientes o recién llegados al juego, es decir, algunos estudiantes que adhieren a sus críticas, validando la illusio de que "pertenecer tendrá sus privilegios». Estudiemos en detalle la estrategia del numerus clausus en estos dos ámbitos de una trayectoria traductora: el formativo y el graduado. 
El primer opositor a este artículo de la LDTyFT fue un grupo de formadoras de nivel superior que se reunieron en el Segundo Ateneo de Traductología, en la Facultad de Humanidades y Ciencias de la Educación de la Universidad Nacional de La Plata en agosto de 20I4. Fruto de este encuentro, elaboraron una carta (Cagnolati y otros) que sumó 300 firmas de adhesión y que presentaron el 3 de noviembre de 2013 al Congreso para adjuntar al expediente del proyecto de ley. Esta carta fue a su vez respondida por otra redactada por docentes de traducción del IEs en Lenguas Vivas «J. R. Fernández» (Álvarez y otros) y que contó con II4 firmas de adhesión, junto con otra carta similar de docentes egresados y estudiantes de Córdoba (Lobo y otros) agrupados en Síntesis-FIL (I8/Io/I4), y que tuvo la adhesión de 28 firmas. Por último, los redactores tanto del proyecto como de las respectivas cartas pudieron verse cara a cara en una mesa de diálogo (24/04/I5) convocada por el Seminario Permanente de Estudios de Traducción del ies en Lenguas Vivas, co-coordinado con el centro de estudiantes de la misma institución (Mársico y otros). ${ }^{6}$

Los formadores opositores (que están, a su vez, graduados en traducción en instituciones universitarias nacionales y extranjeras) leen en la proposición «cualquiera sea su formación» del artículo 2, una clara «desvalorización de la formación de los traductores»: "la figura del traductor diplomado no debería ser ignorada porque funciona como garantía de excelencia» — señalan-y proponen una reformulación del artículo. En su propuesta, refieren sólo al traductor diplomado, pero contemplando excepciones para aquellas personas que por una cuestión generacional no se hubieran podido formar en carreras de traducción (dado que estas se desarrollaron mayormente durante los años setenta y ochenta en el país) o para los traductores de «lenguas huérfanas» (ruso, griego, chino, etc.) que aún no cuentan con carreras específicas, y cuyas dotes traductoras podrían ser evaluadas por un comité de traductores diplomados convocados por el Ministerio de Educación. Aquí la enmienda propuesta y elevada al Congreso por este grupo: son traductores las «personas físicas que realizan la traducción de obras literarias, de ciencias sociales y humanas, científicas y técnicas sujetas a propiedad intelectual compuesta por derechos de autor con título habilitante de Traductorla (universitario o terciario) o formación acreditada equivalente» (en cursiva se destaca el cambio propuesto).

Según esta enmienda, el campo se dividiría entre los traductores diplomados o acreditados por méritos equivalentes frente a los «traductores» no diplomados (comillas en el original), "quienes trabajan para editoriales de manera informal». Los primeros garantizarían la «excelencia» de la profesión, los segundos la «desvalorización» de la misma.

Analicemos esta construcción. En primer lugar, en este razonamiento, la formación es equiparada a la titulación, o sea, a una acción pedagógica certificada por una institución de enseńanza. La titulación acredita, entonces, la posesión de un determinado capital escolar. Siguiendo a Bourdieu en su estudio del sistema educativo en La reproducción (1970), la "excelencia» de este capital escolar adquirido no sería más que una naturalización de un arbitrario cultural, esto es, del 
aprendizaje de una selección que los formadores imponen como «cultura legítima» y sobre el que los estudiantes se dejan examinar, dando muestras de «buena voluntad cultural». Así, los estudiantes que adecuan sus esperanzas subjetivas a las expectativas que se tienen de ellos conciben su trayectoria futura como una sucesión de títulos por adquirir.

Ahora bien, ¿qué pasa cuando este capital escolar acumulado vía múltiples titulaciones (terciario, licenciatura, maestrías, etc.) no garantiza la reconversión en capital económico en el mercado, por caso, en un puesto laboral en el ámbito editorial? Los poseedores de títulos advierten que sus diplomas se devalúan y que necesitan cada vez más títulos para mantener su misma posición real. Pero, en lugar de luchar por una reconversión económica acorde, se concentran en adquirir más capital escolar.

¿Cómo se justifica esta acción? Se puede leer un esbozo de respuesta en la carta del grupo de formadores opositores al proyecto de LDTyFT. Este se muestra convencido de que la devaluación de las titulaciones de traducción provendría del intrusismo de los autodidactas, es decir, de aquellos que carecen de título habilitante pero que trabajan en el mercado editorial. El efecto de la titulación permitiría ennoblecer a quienes la poseen (la «nobleza del título») y estigmatizar o «excepcionalizar», en cambio, a quienes no la detentan. Así pues, «los poseedores de títulos de nobleza cultural están separados por una diferencia innata de los simples plebeyos de la cultura, que están irremediablemente devaluados al estatus dos veces devaluado de autodidacta y de "ejecutante de una función"» (Bourdieu 1979:2I).

Pero, ¿son los que carecen de una titulación específica quienes fomentan esta depreciación de los diplomas? Aplicando la pura lógica de oferta y demanda, la propia inflación de títulos (que claramente los formadores opositores apoyan como signo de «profesionalización» de la carrera de traducción: «el gran pilar del profesionalismo es la formación", declaran en la mesa de diálogo) es lo que determina una devaluación de los mismos; la oferta crece, el producto se deprecia. El irrefrenable aumento de titulaciones conforma una suerte de «burbuja diplomada»; estas ya no apuntan a que el capital escolar se reconvierta en el mercado en un puesto real (o sea, más capital económico), sino que funcionan más bien como «papel moneda académico» (I4I), que permite seguir acumulando más volumen del mismo tipo de capital escolar. Ante esta situación, el comportamiento de los agentes en el sistema educativo es explicado por Bourdieu como un «efecto de alodoxia», es decir, los agentes cometen un error de percepción o apreciación de su posición al querer sostener la illusio del juego: «La alodoxia que el sistema fomenta de mil maneras es lo que hace que los relegados ayuden a su propia relegación al sobrestimar las vías en las que se internan, al sobrevalorar sus titulaciones y al concederse unas posibilidades que en realidad les son negadas, pero también que hacen que no acepten realmente la verdad objetiva de su posición y de sus titulaciones» (I55).

El enmascaramiento de la devaluación es posible porque se recurre a una esencialización de la titulación: la definición del proyecto de LDTyFT que, a los efectos 
de la ley, se presenta como una descripción fenomenológica de una situación laboral de los traductores autorales es leída por los formadores opositores de forma existencial: la existencia es considerada una manifestación de una esencia. Así, los agentes titulados viven su identidad escolar como identidad social e incluso como identidad personal; de ahí también se entiende el interés en parapetarse en un numerus clausus que asegure una homogeneidad protectora respecto de heterodoxas identidades traductoras que amenazarían su ser más íntimo. Dicha esencialización, propia del habitus de los formadores opositores, acarrea como consecuencia que, frente a la imposibilidad de reconversión económica del capital escolar, los poseedores de títulos rehúsen vender su fuerza de trabajo al precio que se les ofrece (I4I). En ese sentido, una de las redactoras de la carta opositora, Ana María Gentile, en la mesa de diálogo, señaló que los traductores formados suelen afirmar respecto de la traducción editorial: «uy yo tanto que me capacité; no voy a ir a trabajar por dos pesos». En cambio, hallan un restablecimiento simbólico en su mundo cercano a través de la mistificación de su posición, alentado tanto por la propia persona como por grupos afines (pares, alumnos, familiares, etc.).

Esta mistificación de los poseedores de títulos devaluados acaba, mal que les pese, haciéndole el juego al mercado editorial, que no hará nada por cambiar las condiciones laborales — al menos hasta que una ley no obligue a los editores a respetar las buenas prácticas a las que a veces adhieren sabiendo que carecen de valor legal (Kalinowski:5o)—. Incluso, si se aceptase la enmienda en el artículo 2, las editoriales podrían limitarse a contratar a traductores sin título habilitante para así evitar pagar derechos de autor, ya que sólo los titulados podrían tener ese derecho. A través de los mecanismos de compensación simbólica y de la adquisición de más capital escolar se enmascara la discontinuidad entre estudio y trabajo y se desanima una lucha real por las condiciones laborales. De ahí que creamos necesario que ocurra «un brusco desenganche de las oportunidades objetivas con respecto a las esperanzas subjetivas» (Bourdieu 1979:I65) para lograr, por fin, un cambio en las representaciones.

En este punto, la demanda de los sectores dominados, que dejan de aceptar la imposición naturalizada de los sectores dominantes, resulta clave. Esto es lo que ocurrió con la polémica sobre el proyecto de LDTyFT en la Universidad de Córdoba. Un grupo de estudiantes (Agrupación Independiente de Estudiantes de Lenguas), docentes y egresados/as de Lenguas (Síntesis FL) se preguntaron, en su carta de apoyo al proyecto de ley, si acumular una sucesión de titulaciones alcanzaba para dar el salto al mercado laboral. La polémica sobre el artículo 2 les concernía especialmente porque, con el mismo espíritu del artículo, el claustro estudiantil de la Facultad de Lenguas había presentado en septiembre de 2014 un proyecto denominado «Programa de Acompañamiento Profesional para Egresados/as Noveles de la Facultad de Lenguas», que apuntaba a que el flamante egresado y futuro trabajador pudiera tener un acompañamiento de un profesional idóneo, con una antigüedad probada de más de diez ańos en el ejercicio de la profesión, más allá de que este último tuviera o no título específico. Este Programa buscaba reparar el 
escaso contacto que durante la carrera se entablaba con las editoriales de Córdoba y el desconocimiento del ámbito editorial por parte de los docentes que formaban a los estudiantes (Seia). El Programa fue criticado, sobre todo, por docentes integrantes del Colegio de Traductores y de la Federación Argentina de Traductores (FAT), que opusieron clara resistencia para que el proyecto siguiera adelante.

Asimismo, en la mesa de diálogo, los estudiantes y egresados señalaron los límites a la circulación de las cartas de apoyo en las listas de distribución, marcando una diferencia entre la carta opositora, que circuló a nivel institucional mucho más fácil que la de los estudiantes:

la nota de ustedes [en referencia a la carta de los docentes de La Plata] tuvo 300 adhesiones y que no siguieron divulgándola, si no, tendría mucha más. Y sí, tuvo muchas más adhesiones pero también, por ejemplo, a nosotros esa nota nos llegó desde la información general de la Facultad de Lenguas, o sea, por una vía oficial, se distribuyó muchísimo más entre los claustros. Y la nota que nosotros escribimos con nuestra posición nunca fue enviada, por más que insistimos y la mandamos a través de esta información general a la Facultad de Lenguas, con lo cual mucha gente no tuvo acceso a nuestra nota. O sea que la cuestión de las adhesiones es discutible porque hay un desequilibrio evidente entre quién tiene el acceso a la divulgación de sus posiciones y quiénes no. (Declaraciones de Natalia Lobo en Mársico y otros)

Estas manifestaciones en apoyo al proyecto de LDTyFT por parte del sector menos poderoso del campo de la traducción, son, no obstante, cruciales para romper con la «ilusión de que les basta esperar para obtener lo que en realidad no obtendrán más que a través de sus luchas» (Bourdieu I979:I63).

El segundo grupo de oposición estuvo conformado por graduados colegiados o federados, sobre todo, por la Federación Argentina de Traductores (FAT) y el Colegio de Traductores Públicos de la Ciudad de Buenos Aires (СтрсвA). Veamos sus tomas de posición.

$\mathrm{Al}$ enterarse del proyecto de ley, la FAT, integrada por Colegios, Consejos Profesionales creados por ley o asociaciones autorizadas, envió una carta de queja a la Asociación Argentina de Traductores e Intérpretes (AATI), porque dos de los miembros de su actual junta directiva son redactores del proyecto. Luego, hicieron pública su oposición en la I Jornada de Traducción para traductores del siglo Xxi de Córdoba (octubre de 20I4) en el panel «Marco legal y debates actuales», con la participación de Víctor Sajoza, docente de la Universidad de Córdoba, miembro del Colegio de Traductores Públicos de Córdoba (CTPC) y de la Fat. En este panel, volvió a quedar patente que la oposición se centraba en la proposición «cualquiera sea su formación». Por un lado, los opositores expresaron la preocupación que, en el futuro, alguien pudiera ampararse en esta Ley para «solicitar una matrícula» sin haber realizado los estudios y/o pruebas correspondientes. Por otro lado, se alarmaron por el desprestigio que sufrirían los títulos que se otorgan en el país; dado que — en los dichos de una docente presente — se abriría una «caja de Pandora» de aprobarse una ley que dijera que es traductor quien traduce. 
Estas intervenciones fueron respondidas, en el mismo panel, por los redactores del proyecto y adherentes señalando, sobre todo, el carácter realista, inclusivo y reparador de la definición de "traductores» en el proyecto de ley. ${ }^{7}$ Por último, ante la invitación a integrar la mesa de diálogo junto con los formadores opositores, la FAT no respondió las reiteradas convocatorias.

El otro grupo que se manifestó en contra fue el СтрсвA. Ante la presentación del segundo proyecto de ley en el Congreso en septiembre de 20I5, el стрсвA convocó de inmediato una reunión para frenar el proyecto, tal como deja ver el fyer con el ícono de la mano roja, firme y en alto que representa un «no pasar». En el texto de la convocatoria, el Consejo Directivo describe el proyecto como elaborado por «algunas personas que se dedican a la traducción», perífrasis que vuelve a presentar como enemigo la figura del «autodidacta» ejecutante. La crítica apunta al artículo 2 y a la defensa de la titulación habilitante: «No podemos aceptar que se reconozca como profesional de nuestra labor a quien no tiene título habilitante, como no lo admitiría la sociedad en ninguna otra profesión. Entendemos que, de aprobarse este proyecto de ley, se está abriendo la puerta para debilitar la figura del traductor y de la traducción en general en nuestro país». El СтрсвA reconoce haber elevado su queja a varios legisladores y convoca a la reunión abierta «debido a la importancia que seguramente le dan todos los matriculados a este tema».

En estas citas de la convocatoria a la reunión, vemos reproducirse la definición del traductor no como el que ejerce la profesión sino como el que posee un título habilitante, pero en este caso, se añade un plus: la importancia (económica, legal y simbólica) de la matrícula entre los traductores públicos y, por lo tanto, una confusión de ámbitos profesionales de incumbencia. Los Colegios fueron creados por la ley 20.305 de 1973, que regula la traducción pública en Argentina, al ser una profesión que atañe el bien general de la población, como otras como medicina, derecho, etc. En esta ley se plantea la creación de un Colegio que cumpla las funciones de registro y control de los traductores públicos, quienes están obligados a pagar una matrícula para su ejercicio profesional; actualmente el СтрсвA cuenta con 8500 matriculados.

Ahora bien, muchos traductores públicos matriculados se dedican también a otro tipo de traducción, ya sea técnico-científica o literaria. Por ejemplo, en la página web del Colegio, vemos que existen tres comisiones temáticas: Audiovisual, Cultura y Ciencia y Técnica, que organizan cursos presenciales y a distancia, actos y conferencias sobre estas áreas. También existe una Comisión de traductores noveles, categoría que definen como aquellos traductores que cuentan «con menos de cinco años de matrícula».

En estos ejemplos, advertimos un desplazamiento y ampliación del área de incumbencia de la matrícula, como permiso de ejercicio, hacia otras categorías o ámbitos que no la requieren. Es decir, un traductor público necesita estar matriculado para traducir documentos legales (por Ley 20.305); en cambio, esta misma matrícula no le es requerida ni lo coloca en una posición de ventaja para traducir 
documentos literarios, científico-técnicos o audiovisuales y menos aun para considerarse un traductor novel o experimentado según los años de matriculación.

Al operar este desplazamiento del sentido, los Colegios argentinos (tanto el CTPCBA como casi todos los colegios provinciales nucleados por la FAT), que cuentan con una base enorme de socios cautivos y, por lo tanto, de recursos económicos, se apropian de la designación de «traductor» (a secas) como única identidad posible de la profesión, tal y como nos deja ver la sigla de la FAT (Federación Argentina de Traductores). Del nombre pasan a la existencia, ya que también extienden su modo de actuar en su subcampo de especialidad (la traducción pública) hacia otros subcampos, como el literario o el audiovisual. Y en ellos aplican sus criterios legales (la posesión de matrícula para ejercer la profesión) desconociendo completamente cómo se desarrollan las trayectorias en estos espacios específicos. Se daría nuevamente aquí un efecto de alodoxia: los agentes matriculados sólo perciben y conciben su práctica profesional como la única válida aun en campos que operan con otra lógica.

Ahora bien, la traducción autoral funciona más próxima a la lógica del campo artístico, ya que está más ligada a la creación que a la validación de la verdad de un documento oficial. La trayectoria de un traductor autoral se acerca más a la de un escritor.

Soy traductor profesional desde hace más de treinta años. He trabajado para muchas de las editoriales más importantes de Argentina y España (Losada, Anagrama, Tusquets, Edhasa, Planeta, Norma y otras) y traducido del inglés, francés y portugués más de 120 libros de narrativa, ensayo y poesía, desde William Shakespeare hasta autores de narrativa más contemporánea. He escrito ensayos sobre la tarea del traductor y he sido honrado con premios.

Esta nota biográfica es la del escritor Marcelo Cohen (2015), en una carta que hizo pública el I9 de octubre de 20I5, a la diputada Nora Bedano (firmante del proyecto LDTyFT) para que no atendiera las modificaciones pedidas por los Colegios sobre la obligatoriedad del título habilitante. Cohen se pone como ejemplo de un colectivo de traductores que cuentan con una innegable formación intelectual (con estudios en el ámbito de las Letras o las Humanidades, desarrollo de una escritura propia o formación en el ámbito editorial):

Mi caso no sería el único, ni mucho menos. Decenas de nuestros mejores traductores, reconocidos en el mundo y por los lectores, carecen de título específico - aunque muchos tienen otros títulos, y desde luego una sólida formación-. Aparte del perjuicio y las aflicciones que conllevaría para ellos, la calidad de nuestra producción editorial de textos traducidos sufriría una merma incalculable.

Justamente en el campo creador, según analiza Gisèle Sapiro (46-48), el desarrollo profesional del oficio de escritor está débilmente reglamentado y cuenta con una multiplicidad de instancias de legitimación que contribuyen a la definición de la literatura (premios, publicación en editoriales prestigiadas, reseñas en 
prensa cultural, etc.); es decir, no existe una única instancia legitimadora como podría ser una matrícula o un título habilitante.

Asimismo y producto de la cercanía con el oficio de escritor, respecto del habitus del traductor autoral, éste suele definirse como un sujeto solitario que se rige más bien por el principio del «interés por el desinterés» propio del campo artístico, tal y como analizan las investigadoras Isabelle Kalinowski (47-54) y Rakefet Sela-Sheffy (I-26). A partir de entrevistas en profundidad, estas investigadoras concluyen que, regido por un imaginario artístico, el traductor literario acaba aceptando condiciones laborales muy precarias, que serían denunciadas por explotación en otras profesiones. Por un lado, Kalinowski señala que la vocación al trabajo de los traductores literarios se adecua fatalmente a la vocación al rédito de quienes encargan el trabajo. Parafraseando a Bourdieu, el estigma se vuelve emblema, la precariedad laboral es vivida como condición de posibilidad de una libertad ascética. Por otro lado, Sela-Sheffy focaliza en el carácter ambiguo de este subcampo, ya que, como profesión, su organización y militancia es débil (hay atomización de grupos y asociaciones, carecen de un código deontológico, etc.) y, como oficio artístico, resulta una ocupación intelectual carente de glamour, es decir, con poco valor simbólico si se compara con la de escritor.

Para concluir, luego del desarrollo de las distintas decisiones, posiciones y disposiciones de los agentes interpelados en el debate sobre la definición de la figura del traductor, creo haber dado muestras de que el proyecto de LDTyFT ha contribuido sobradamente a dar dinamismo al campo de la traducción en Argentina, a cuestionar la estrategia del numerus clausus que tratan de imponer los sectores dominantes de la profesión y a advertir los efectos de alodoxia presentes en las definiciones de «traductor» propuestas por los dos grupos contrarios, que, por un lado, hace que los opositores formadores vean en la reproducción de títulos una garantía de formación y no una devaluación de los mismos y que, por otro, lleva a los opositores colegiados a desplazar su modus operandi a un campo que se dinamiza con otra lógica económica, legal y simbólica. Asimismo, permite reflexionar sobre el habitus del traductor autoral, rompiendo con ciertas inercias de percepción y pensamiento y llamando a la acción organizativa para mejorar sus condicionales laborales. De promulgarse algún día, Argentina tendrá un marco legal que proteja los derechos laborales de un colectivo plural de traductores, todos formados (con o sin titulación habilitante) y, sobre todo, poseedores de un cuerpo que se mueve, alimenta y reflexiona.

\section{Notas}

${ }^{1}$ El proyecto de ley de Derechos de los Traductores y Fomento de la Traducción en Argentina perdió vigencia parlamentaria en diciembre de 2016. Actualmente está en elaboración un tercer proyecto. Asimismo, el grupo

de trabajo inicial se amplió hasta conformar el Frente de Apoyo a la Ley de Traducción Autoral, que se constituyó en la jornada abierta celebrada en el Centro Cultural de la Cooperación de Buenos Aires, el 5 de noviembre de 2016. 
2 Para un mayor desarrollo sobre el marco legal, véase la fundamentación al proyecto de ley Derechos de los Traductores y Fomento de la Traducción (Consigli y otros).

${ }^{3}$ Esta y la siguiente cita han sido extraídas de contratos efectivamente firmados con editoriales argentinas o con sede local. Por confidencialidad, mantenemos el anonimato de los firmantes.

4 Para una lectura de las dos versiones del proyecto, véanse los expedientes 6534-D-2013 y 4852-D-20I5 (Consigli y otros 2013, 2015).
${ }^{5}$ El primer proyecto (6534-D-2013) añadía a «sujetas a propiedad intelectual» la proposición "compuesta por derechos de autor», que se eliminó en su segundo versión por ser redundante y no especificativa.

${ }^{6}$ Las citas textuales aparecen entrecomillas y fueron extraídas tanto de las cartas como de las actas de reunión, que pueden consultarse en el Blog del Frente de Apoyo al proyecto de LDTyFT, sección «Exposiciones».

7 Véanse los informes elaborados por Mársico y Síntesis FL.

\section{Bibliografía}

Álvarez, CeCilia y Otros (20I4). «Figura del traductor». Consultado el 3I de octubre de 2016 en http://everyoneweb.com/wa/DataFilesalemanı2/NotaFiguradelTraductorLLVVı7ı2.pdf BENSEÑOR, JULIA (20I5). «Anochecer de un día agitado». Club de traductores literarios [en línea]. Blog. Consultado el 3i de octubre de 2016 en http://clubdetraductoresliterariosdebaires.blog spot.com.es/2015/1o/anochecer-de-un-dia-agi tado.html BOURDIEU, PIERRE; JEAN-CLAUDE CHAMBOREDON y JEAN-PIERRE PASSERON (1973). El oficio de sociólogo. Madrid: Siglo XXI, 2003. Traducción de Fernando Hugo Azcurra. BOURDIEU, PIERRE (1970). La reproducción. Elementos para una teoría del sistema de enseñanza. Barcelona: Laia, 198I. Traducción de E. L., revisado por J. Melendres y J. Subirats. (1979). La distinción. Criterio y bases sociales del gusto. Madrid: Taurus, 1988. Traducción de María Carmen Ruiz de Elvira Hidalgo. (1984). Questions de sociologie. París, Minuit.

(1987). Cosas Dichas. Barcelona: Gedisa, 1996. Traducción de Margarita Mizraji. CAGNOLATI, BEATRIZY OTROS (2OI4). «Protección del traductor». Consultado el 3I deoctubre de 2016 en http://www.everyoneweb.com/wa/DataFilesalemanı2/NotaCagnolatiGentileZaparart.pdf COHen, MARCElo (2015). «Carta a la diputada Nora Bedano». Frente de apoyo del proyecto de ley de Derechos de los Traductores y Fomento de la Traducción [en línea]. Facebook. Consultado el 3I de octubre de 2016 en https://www.facebook.com/profile.php?id=I00009I49925542\&fref=ts COlegio de traductores públicos de la CiUdad de buenos aires (Ctpcba) [en línea]. Web.

Consultado el 3I de octubre de 2016 en http://www.traductores.org.ar/ consigli, estela y otros (2013). Proyecto de Ley de Protección de la Traducción y los Traductores (6534-D-2013). Consultado el 3I de octubre de 2016 en http://www.diputados.gov.ar/proyectos /proyectoTP.jsp?id=156307 (2015). Proyecto de Ley del Derecho de los Traductores y Fomento de la Traducción

(4852-D-20I5). Consultado el 31 de octubre de 2016 en http://www.diputados.gov.ar/sesiones/proyectos/proyecto.jsp?id=I798I8 FRENTE DE APOYO AL PROYECTO DE LEY DE DERECHOS DE LOS TRADUCTORES Y FOMENTO DE LA TRADUCCión [en línea]. Blog. Consultado el 3I de octubre de 2016 en http://leytraduccion autoral.wixsite.com/traduccionautoral 
KALINOWSKI, ISABELle (2002). "La vocation au travail de traduction». Actes de la Recherche en Sciences Sociales I44, 47-54.

LEY DEL TRADUCTOR PÚBLICO (20.305/1973). Consultada el 3I de octubre de 2016 en http://www. traductores.org.ar/ley-20305

LOBO, NATALIA Y OTROS (20I4). «Sobre la protección del traductor». Consultado el 3I de octubre de 2016 en http://everyoneweb.com/wa/DataFilesalemanı2/Sobrela»proteccióndeltraductor» 3dic.pdf

MÁRSICO, GRISELDA (20I4). "Presentación del proyecto de ley». I Jornada de Traducción para traductores del siglo XXI. Universidad Nacional de Córdoba, Facultad de Lenguas. Consultado el 3I de octubre de 2016 en http://everyoneweb.com/wa/DataFilesalemanı2/IJornadade TraducciónCórdoba.pdf

MÁRSICO, GRISELDA Y OTROS (2OI5). Mesa de diálogo del SPET: «¿Quién puede traducir? En torno a la definición del traductor en el proyecto de ley de traducción autoral» [desgrabación]. Consultado el 3I de octubre de 2016 en http://everyoneweb.com/wa/DataFilesalemanı/ Mesadediálogo244Desgrabación.pdf SAPIRO, Gisèle (20I4). La Sociologie de la littérature. París: La Découverte. SEIA, LuIS (2015). "Informe ¿Quién puede traducir? Derivaciones del proyecto de Ley de Traducción Autoral». Consultado el 3I de octubre de 2016 en http://everyoneweb.com/wa/ DataFilesalemanı//nformeQuienpuedetraducirCordoba.pdf SELA-SHEFFY, RAKEFET (2005). «How to be a (recognized) translator». Target I7(I), I-26. SíNTESIS FL (20I4). «Informe I Jornada de Traducción para traductores del siglo XXI». Universidad Nacional de Córdoba, Facultad de Lenguas. Consultado el 3I de octubre de 2016 en http:// everyoneweb.com/wa/DataFilesalemanı2/InformeJornadasS\%C3\%ADntesis26II.pdf 